\title{
Effect of Synthetic Parameters on Synthesis of Magnesium Aluminum Spinels
}

\author{
Jinxia Duan1, Xiuhui Wang1, Youfei Zhang1, Hong Gao¹, Yan Xie ${ }^{2 *}$, Jinlong Yang ${ }^{3}$ \\ ${ }^{1}$ School of Materials and Engineering, Dalian Jiaotong University, Dalian, China \\ ${ }^{2}$ Gold Catalysis Research Center, State Key Laboratory of Catalysis, Dalian Institute of Chemical Physics, Chinese Academy of \\ Sciences, Dalian, China \\ ${ }^{3}$ State Key Laboratory of New Ceramics and Fine Processing, School of Materials Science and Engineering, Tsinghua University, \\ Beijing, China \\ Email: *yanxie@dicp.ac.cn
}

How to cite this paper: Duan, J.X., Wang, X.H., Zhang, Y.F., Gao, H., Xie, Y. and Yang, J.L. (2019) Effect of Synthetic Parameters on Synthesis of Magnesium Aluminum Spinels. Journal of Materials Science and Chemical Engineering, 7, 1-15. https://doi.org/10.4236/msce.2019.73001

Received: February 3, 2019

Accepted: March 24, 2019

Published: March 27, 2019

Copyright $\odot 2019$ by author(s) and Scientific Research Publishing Inc. This work is licensed under the Creative Commons Attribution International License (CC BY 4.0).

http://creativecommons.org/licenses/by/4.0/

\begin{abstract}
In this work, the magnesium aluminum spinel $\left(\mathrm{MgAl}_{2} \mathrm{O}_{4}\right)$ was prepared by $\mathrm{Mg}$ and $\mathrm{Al}$ as precursors through a method of sol-gel subsequent with high temperature calcination. The wide range of synthetic conditions, including organic alcohols, ammonia content, dispersant, alkoxide concentration, hydrolysis time, hydrolysis temperature and calcination temperature were screened over as-prepared samples. This work provides a necessary experimental basis for the synthesis of $\mathrm{MgAl}_{2} \mathrm{O}_{4}$ with uniform particle size of spherical structure, which has a potential to be used in many industrial and military applications.
\end{abstract}

\section{Keywords}

Alkoxide Hydrolysis, $\mathrm{MgAl}_{2} \mathrm{O}_{4}$, Synthetic Parameters

\section{Introduction}

As one of well-known spinels (typically refers to $\mathrm{AB}_{2} \mathrm{O}_{4}, \mathrm{~A}^{2+}, \mathrm{B}^{3+}$ or $\mathrm{A}^{4+}, \mathrm{B}^{2+}$ ), magnesium aluminate $\left(\mathrm{MgAl}_{2} \mathrm{O}_{4}\right)$ has been mainly developed and applied in industrial and military applications, including high-pressure arc lamps, transparent armor, optical heat exchangers, and missile domes [1] [2] [3] [4] [5]. Among them, appropriate transparent ceramic based materials were employed due to its unique properties, like high thermal stability with high melting point of $2135^{\circ} \mathrm{C}$ [6], unique optical properties and mechanical strength at high temperature. With increasing utilizations of catalyst and support, $\mathrm{MgAl}_{2} \mathrm{O}_{4}$ spinel has been synthesized with high purity, small particle size with uniform pore size 
distribution and high surface area. Therefore, it is crucial to widely investigate on the synthetic parameters of $\mathrm{MgAl}_{2} \mathrm{O}_{4}$ [7]. So far, several approaches were introduced for the preparation of $\mathrm{MgAl}_{2} \mathrm{O}_{4}$, namely solid-state [8] [9], sol-gel [10] [11] [12] [13], spray drying [14] and co-precipitation [15] [16]. Especially, sol-gel is considered to be one of the most effective methods focused on the synthesis of $\mathrm{MgAl}_{2} \mathrm{O}_{4}$. Any positive ions can be introduced during the hydrolysis process. Besides, the reaction conditions of alkoxide hydrolysis are mild with various advantages, such as simple operation, high purity of product and small particle size, leading to the final high activity. It is known that alkoxide hydrolysis has been extensively used not only on the development of nano-alumina powder but also on the synthesis of $\mathrm{MgAl}_{2} \mathrm{O}_{4}$ [17] [18]. To the best of our knowledge, few investigations were reported on the synthetic parameters for preparation of $\mathrm{MgAl}_{2} \mathrm{O}_{4}$ via alkoxide hydrolysis [18]. Great efforts have been made on the features of metal alkoxides, particularly in the preparation of high-purity oxide powders of uniform size, shape as well as the composition.

Herein, discussion on the synthetic parameters on $\mathrm{MgAl}_{2} \mathrm{O}_{4}$ through alkoxide hydrolysis was introduced by $\mathrm{Mg}\left[\mathrm{Al}(\mathrm{OR})_{4}\right]_{2}$ derived from $\mathrm{Mg}, \mathrm{Al}$ and isopropanol by tuning the reaction conditions and synthetic factors. In this work, several synthetic influenced factors (especially refer to type of organic alcohol, $\mathrm{pH}$, aging time, temperature, etc.) were considered on the effect of the structure and size distribution of as-acquired samples.

It has been known that three reactions simultaneously occur based on hydrolysis theory for alkoxide, namely 1 ) hydrolysis reaction process

$\left(\mathrm{M}-\mathrm{OR}+\mathrm{H}_{2} \mathrm{O} \rightarrow \mathrm{M}-\mathrm{OH}+\mathrm{R}-\mathrm{OH}\right.$ ); polycondensation reaction of 2)

$\mathrm{M}-\mathrm{OR}+\mathrm{HO}-\mathrm{M} \rightarrow \mathrm{M}-\mathrm{O}-\mathrm{M}+\mathrm{ROH}$ and 3$)$

$\mathrm{M}-\mathrm{OH}+\mathrm{HO}-\mathrm{M} \rightarrow \mathrm{M}-\mathrm{O}-\mathrm{M}+\mathrm{H}_{2} \mathrm{O}$. It is believed that the hydrolysis of $\mathrm{MgAl}_{2}\left(\mathrm{OC}_{3} \mathrm{H}_{8}\right)_{8}$ is incomplete with much lower content of water. The hydrolysis rate is boosted at the point of too much water. The hydrolyzed product of $\mathrm{MgAl}_{2}(\mathrm{OH})_{8}$ incompletely disperse, resulting in agglomeration and enlargement of the particles. Therefore, moderate of hydrolysis rate is favorable to obtain uniform particle size with well-dispersibility at $40^{\circ} \mathrm{C}$ for $24 \mathrm{~h}$ with CTAB at $\mathrm{pH}$ value of 8.5. As a result, the obtained $\mathrm{MgAl}_{2}(\mathrm{OH})_{8}$ was further calcined at $1200^{\circ} \mathrm{C}$ for preparation of $\mathrm{MgAl}_{2} \mathrm{O}_{4}$. This study further opens a new avenue to supply an optimal synthetic route to achieve pure metal oxides by hydrolysis, which can be widely applicated in the fields of industrial production and military applications.

\section{Experimental}

\subsection{Chemicals}

$\mathrm{Mg}$ foil (99.9\%), $\mathrm{Al}$ foil (99.9\%) and Anhydrous aluminum chloride (AR) were obtained from Tianjin Bodi Chemical Co., Ltd. Cetyltrimethylammonium bromide (CTAB, AR) and polyvinyl pyrrolidone (PVP) were purchased from Shanghai Reagents Factory. $\mathrm{AlF}_{3} \cdot 3 \cdot 5 \mathrm{H}_{2} \mathrm{O}(\mathrm{CP})$ was got from Shanghai Reagent 
Third Factory. Alcohol (AR), isopropanol (AR) and n-butanol (AR) were obtained from Liaodong Chemical Reagent Factory. The deionized water was directly made in the experiment.

\subsection{Preparation of $\mathrm{MgAl}_{2} \mathrm{O}_{4}$}

Preparation of alkoxide: $\mathrm{Mg}$ and $\mathrm{Al}$ foils were first grinded and cleaned with ethanol. The treated $\mathrm{Mg}$ and $\mathrm{Al}$ were weighed and added into the reaction kettle based on the stoichiometric ratio of $\mathrm{MgAl}_{2} \mathrm{O}_{4}$ with the addition of trace $\mathrm{AlF}_{3}$ and excess isopropanol. After heated at $85^{\circ} \mathrm{C}$ under reflux, the product of $\mathrm{MgAl}_{2}\left(\mathrm{OC}_{3} \mathrm{H}_{8}\right)_{8}$ was obtained after distillation. Here, in the experiment organic alcohols of ethanol and n-butanol were selected under reflux at corresponding boiling point for comparison.

Alkoxide hydrolysis: Organic alcohol and deionized water were prepared to hydrolysate with a volume ratio of $1: 1 . \mathrm{NH}_{3} \cdot \mathrm{H}_{2} \mathrm{O}(1.5 \mathrm{~mL})$ and $\mathrm{CTAB}(0.75 \mathrm{~mL})$ were added into $50 \mathrm{~mL}$ above hydrolysate stirring under constant temperature water bath. Colorless transparent sol of $\mathrm{MgAl}_{2}(\mathrm{OH})_{8}$ was obtained by addition of $10 \mathrm{~g} \mathrm{MgAl}{ }_{2}\left(\mathrm{OC}_{3} \mathrm{H}_{8}\right)_{8}$ with dropwise at a rate of $0.1 \mathrm{~mL} \cdot \mathrm{min}^{-1}$ under continuous stirring in the water bath at $40^{\circ} \mathrm{C}$ for $24 \mathrm{~h}$. In this experiment procedure, several synthesis parameters, like alkoxide addition amount, proportion of isopropanol and deionized water in hydrolysate, hydrolysis temperature and time, $\mathrm{pH}$ value, the addition of dispersant (refers to CTAB and PVP) were further investigated keeping other parameters consistent.

Preparation of $\mathrm{MgAl}_{2} \mathrm{O}_{4}$ : The $\mathrm{MgAl}_{2}(\mathrm{OH})_{8}$ sol synthesized via alkoxide hydrolysis was further dried at $80^{\circ} \mathrm{C}$ for $4 \mathrm{~h}$ and calcined at $1200^{\circ} \mathrm{C}$ for $2 \mathrm{~h}$ in a box-type resistance furnace. As a result, the sample of magnesium aluminum spinel powder was obtained for further characterization.

\subsection{Characterization}

The weight loss was tested by TGA (600, USA, TAQ) under $\mathrm{N}_{2}$ with warming speed of $5^{\circ} \mathrm{C} \cdot \mathrm{min}^{-1}$. X-ray diffraction (XRD) analysis was recorded on a $\mathrm{D} /$ max-3B X-ray diffractometer ( $\mathrm{CuK} \alpha$ radiation, $\lambda=1.54056 \AA$ ) to detect the structure of samples in a scanning range $2 \theta$ of 5 to $80^{\circ}$ with operating voltage at $40 \mathrm{kV}$ and the current of $35 \mathrm{~mA}$ with a scanning rate of $2^{\circ} \cdot \mathrm{min}^{-1}$. The Brunauer-Emmet-Teller (BET) specific surface area and porous properties were measured through $\mathrm{N}_{2}$ adsorption-desorption at $-196^{\circ} \mathrm{C}$ on a Quadrasorb SI instrument (Quantachrome, USA). A field-emission scanning electron microscope (SEM) was operated on a JSM-6360LV instrument (JEOL Corporation) to describe the morphology of samples at the accelerating voltage of $5.0 \mathrm{kV}$. A mater sizer 2000 laser particle size analyzer (Malvern Corporation, UK) was used to measure the particle size and its distribution.

\section{Results and Discussion}

\subsection{Effect on Organic Alcohols}

Initially, different organic alcohols, including ethanol, isopropanol and n-butanol 
were selected to investigate its effect on the particle size of precursors. The particle size and surface area of corresponding samples are listed in Figure 1 and Table 1. It can be seen that the particle size distribution of powder prepared with ethanol and isopropanol is relatively concentrated compared to that of powders synthesis with $n$-butanol. The sample with $n$-butanol possesses twice as much as that at D90 (the cumulative particle size distribution of a sample reaching $90 \%$ ) relative to other two samples. It might be the reason that partially negatively charged $\mathrm{HO}^{\delta}$ group nucleophilic attack with a partially positively charged metal atom $\mathrm{M}^{\delta+}$ during the hydrolysis process. Meanwhile, positively charged protons are transferred to a negatively charged $\mathrm{OR}^{\delta}$. Finally, the protonated protonated $\mathrm{OR}^{\delta+}$ is separated from the metal atom $\mathrm{M}$. The large molecular structure of magnesium n-butoxide results in relatively weak between alkoxy $\mathrm{OR}^{\delta+}$. Metal bond and $\mathrm{OR}^{\delta+}$ rapidly desorbs from the metal atom to form magnesium hydroxide aluminum particles leading to hydrogen hydroxide in a short time. Besides, the particles are easier to agglomerate and consequently the particle size of corresponding powder with n-butanol has a relatively dispersion. With comprehensive analysis of samples with different alcohols, the sample with isopropanol displays a larger surface area with uniform particle size.

\subsection{Effect of Ammonia Content}

The concentration of ammonia was also taken accounted in the synthesis of hydrolysis magnesium aluminum alkoxide, in which ammonia was used to adjust

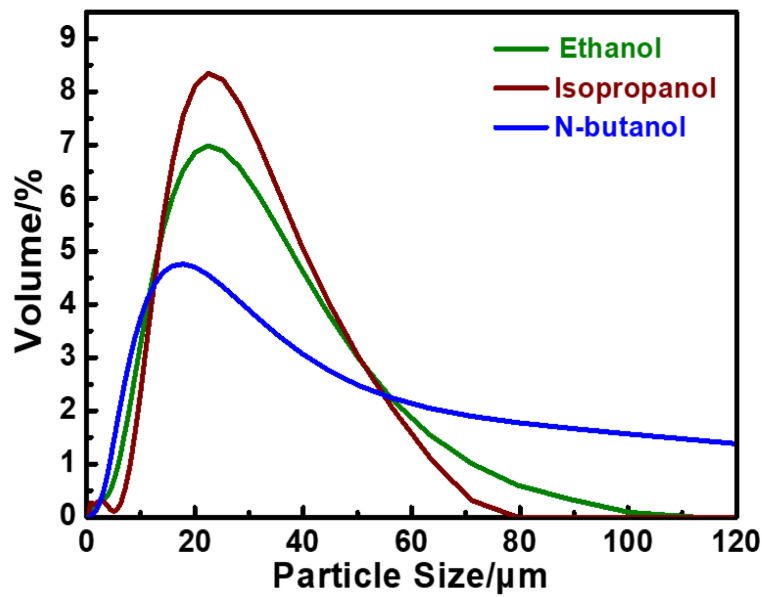

Figure 1. The size distribution of alkoxides with various alcohols of ethanol, isopropanol and n-butanol.

Table 1. The particle size and specific surface area of samples with various alkoxides.

\begin{tabular}{ccccc}
\hline $\begin{array}{c}\text { Alkoxides with } \\
\text { types of alcohols }\end{array}$ & D10 $(\mu \mathrm{m})$ & D50 $(\mu \mathrm{m})$ & D90 $(\mu \mathrm{m})$ & $\begin{array}{c}\text { Surface area } \\
\left(\mathrm{m}^{2} / \mathrm{g}\right)\end{array}$ \\
\hline Ethanol & 7.439 & 19.719 & 43.041 & 5.16 \\
Isopropanol & 9.621 & 20.874 & 40.475 & 5.51 \\
N-butanol & 6.280 & 19.932 & 102.283 & 4.47
\end{tabular}


the $\mathrm{pH}$ value of the system. Figure 2 displays the ammonia concentration effect on the particle size and size distribution of powders hydrolysis at $20^{\circ} \mathrm{C}$ for $2 \mathrm{~h}$. Obviously, the average particle size gradually increases with the increasing ammonia content from 0.5 to $3.0 \mathrm{~mL}$. The well-dispersion of powder with $0.5 \mathrm{~mL}$ ammonia content can be acquired by scanning electron microscope (SEM) in

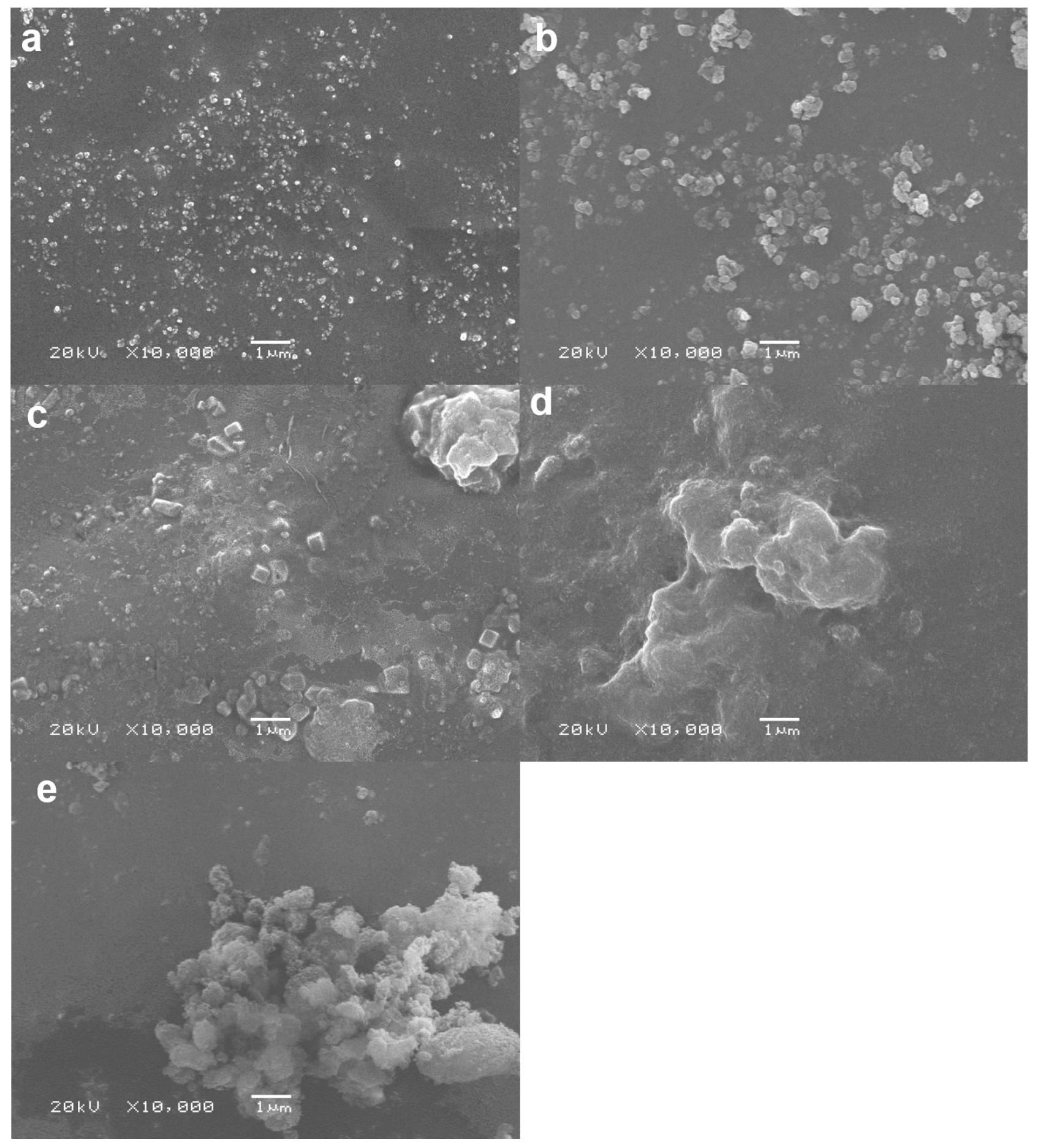

Figure 2. SEM images of powders hydrolysis at $20^{\circ} \mathrm{C}$ for $2 \mathrm{~h}$ with different addition of ammonia: (a) $0.5 \mathrm{~mL}$, (b) $0.75 \mathrm{~mL}$, (c) 1.0 $\mathrm{mL}$, (d) $2.0 \mathrm{~mL}$ and (e) $3.0 \mathrm{~mL}$. 
Figure 2(a). In particular, the particle grows a little larger with uniform and well-dispersion at a point of $0.75 \mathrm{~mL}$ of ammonia content in Figure 2(b), and the $\mathrm{pH}$ value is measured to be 8.5. Clearly, blocks are detected in Figure 2(c) to Figure 2(e), indicating that severe agglomeration occurs in excess alkaline solutions. During the step of $\mathrm{MgAl}_{2}\left(\mathrm{OC}_{3} \mathrm{H}_{8}\right)_{8}$ hydrolysis in an alkaline environment, the negatively charged $\mathrm{Mg}$ and $\mathrm{Al}$ nuclei appear by directly attacked by small anion $\mathrm{OH}^{-}$radius, leading the cloud shift to the $\mathrm{OR}$ group on the other side. This further weakens the M-O bond and breaks out of the OR, and finally completes the hydrolysis reaction. With trace addition of ammonia, the rate of hydrolysis is relatively slow. At this point, it can be immediately spread widely to surroundings. That is, when the forming-speed of particles is smaller than that of the diffusion speed, the hydrolysis of $\mathrm{MgAl}_{2}\left(\mathrm{OC}_{3} \mathrm{H}_{8}\right)_{8}$ acquires a very small particle size with a uniform particle size distribution. Continue to increase the amount of ammonia, the higher concentration of $\mathrm{OH}^{-}$may enhance the hydrolysis rate and rate of colloidal particles. At that time, the agglomerates can be easily observed. Therefore, the controlling of $\mathrm{pH}$ in the hydrolysis process not only affects the gelation process but also plays a key role in the colloidal aggregation process. After all, the ideal hydrolysis $\mathrm{pH}$ is tuned to be 8.5 based on the formation in Figure 2.

The size distribution of samples with different addition of ammonia is listed in Figure 3 and Table 2. As the increasing of ammonia, the particle size of the

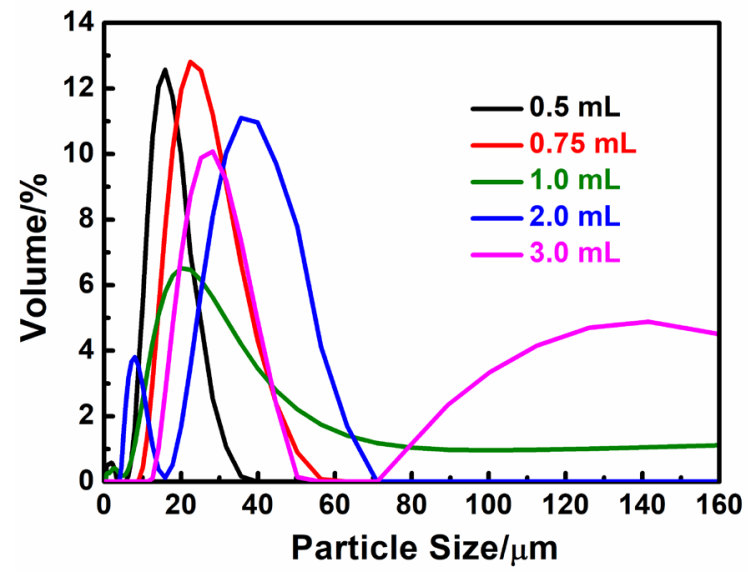

Figure 3. The size distribution of powders with different addition of ammonia from $0.5 \mathrm{~mL}$ to $3.0 \mathrm{~mL}$.

Table 2. The particle size powders with different addition of ammonia in the range of 0.5 $\mathrm{mL}$ to $3.0 \mathrm{~mL}$.

\begin{tabular}{cccc}
\hline Ammonia $(\mathrm{mL})$ & D10 $(\mu \mathrm{m})$ & D50 $(\mu \mathrm{m})$ & D90 $(\mu \mathrm{m})$ \\
\hline 0.5 & 7.748 & 14.147 & 21.867 \\
0.75 & 14.103 & 21.882 & 33.994 \\
1.0 & 8.878 & 22.290 & 139.183 \\
2.0 & 6.859 & 30.122 & 46.990 \\
3.0 & 18.303 & 30.309 & 145.884 \\
\hline
\end{tabular}


powder increases. With addition of $0.5 \mathrm{~mL}$ ammonia, it shows a main peak with the average particle size of $14.15 \mu \mathrm{m}$ and a small peak around $2.0 \mu \mathrm{m}$, indicating that the higher proportion of small particles in the powder. When the amount of ammonia increases to $0.75 \mathrm{~mL}$, there is a single peak with an average particle size of $21.88 \mu \mathrm{m}$. It further confirms that the particle size distribution is uniform with well agreement of SEM images in Figure 2. With continuously increased amount of ammonia, the particle size of the powder is gradually increased. When the amount of ammonia is $2.0 \mathrm{~mL}$, the particle size is observed as two obvious distribution areas. There is no further no difference in the average particle size of the powder but the uniformity of particles deteriorates along with further excessive ammonia.

\subsection{Effect of Dispersant during Hydrolysis}

Dispersant, like CTAB and PVP, was selected to screen the particle distribution of samples. SEM images in Figure S1 clearly exhibits that the spherical particle is obtained with the dispersant of CTAB, which is very different from that of sample with PVP. It further indicates that only certain dispersant of CTAB is benefit for creation the feature of particles. More importantly, we also compared the difference between the samples with or without CTAB dispersant for preparation of $\mathrm{MgAl}_{2} \mathrm{O}_{4}$. The SEM image in Figure 4(a) exhibits that the agglomeration phenomenon is accessible without any dispersant. However, well-dispersion with spherical particles are obtained in Figure 4(b). Based on the tendency described in Figure 4(c) and Table 3, the particle size of sample without any dispersant is centered to be about $43 \mu \mathrm{m}$ and the distribution is unconcentrated. In contrast, the addition of $\mathrm{CTAB}$ greatly changes this phenomenon. The particle size decreases with the increase of CTAB content. Different amount of CTAB
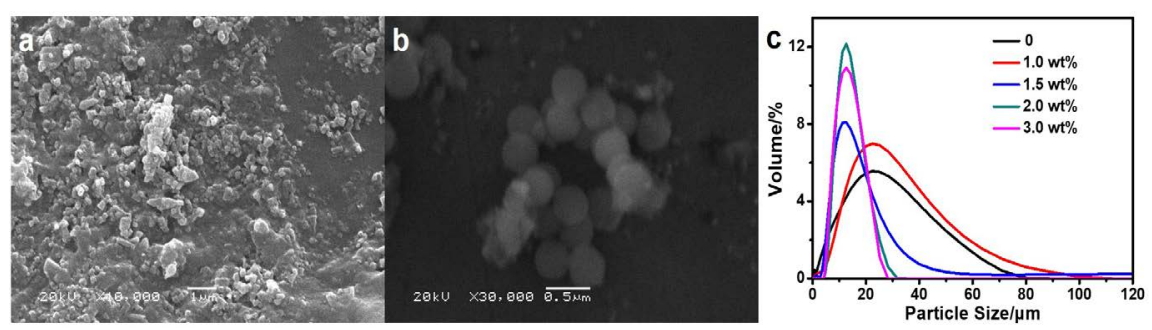

Figure 4. SEM images of $\mathrm{MgAl}_{2} \mathrm{O}_{4}$ : (a) without CTAB; (b) with $1.5 \mathrm{wt} \% \mathrm{CTAB}$ and (c) the size distribution of samples with various amount of CTAB.

Table 3. The particle size of samples with different amount of CTAB.

\begin{tabular}{cccc}
\hline Dispersant amount $(\mathrm{wt} \%)$ & $\mathrm{D} 10(\mu \mathrm{m})$ & $\mathrm{D} 50(\mu \mathrm{m})$ & $\mathrm{D} 90(\mu \mathrm{m})$ \\
\hline 0 & 7.439 & 19.719 & 43.041 \\
1.0 & 3.557 & 17.474 & 43.054 \\
1.5 & 5.738 & 11.610 & 25.141 \\
2.0 & 7.271 & 11.667 & 18.483 \\
3.0 & 6.662 & 11.265 & 18.056 \\
\hline
\end{tabular}


was screened from 0 to $3.0 \mathrm{wt} \%$ to further detect the particle size and its distribution in Figure 4(c), indicating that the crucial factor of dispersant amount in the synthesis process. Especially for the point of $1.5 \mathrm{wt} \%$, the particle size is greatly reduced and the distribution begins to concentrate. After that, the continuously increased amount of CTAB results in no more changes for particle size.

\subsection{Effect of Alkoxide Concentration}

SEM images in Figure 5 illustrate the influenced concentration of $\mathrm{MgAl}_{2}\left(\mathrm{OC}_{3} \mathrm{H}_{8}\right)_{8}$ on the morphology of hydroxides. The $\mathrm{MgAl}_{2} \mathrm{O}_{4}$ powder by introduction of $5 \mathrm{~g}$ alkoxide (Figure 5(a)) leads to a mixture of spherical particles and flocculent agglomerates. The average size of particles is determined to be about $400 \mathrm{~nm}$. Some spherical particles are damaged and single spherical particle is found to aggregate with floc on the surface. Increasing the amount of alkoxide to $10 \mathrm{~g}$ in Figure 5(b), it is found that spherical particles gradually decrease and agglomerate. The size distribution of floc aggregates is uneven and the boundary is irregular. With the addition of $15 \mathrm{~g}$ alkoxide in Figure 5(c), spherical particles substantially disappear resulting in a white floc hydrolysate with a relatively uniform distribution with well dispersion, in which several opaque particles intersperse. It can be seen that alkoxide concentration has a great influence on the formation of colloids and particles during the hydrolysis reaction. It believes that it is mainly attributed to the extremely low concentration of alkoxide solution results in the restricted growth of nucleus to form sol. With increasing high concentration of alkoxide solution, the rapid formation of the nucleus under the state of supersaturation causes the crystal grains to have insufficient growth leading to small particle colloid. It is favorable for the growth of particles to form precipitates with moderate amount. In this work, it demonstrates that the sample with $10 \mathrm{~g}$ alkoxide possesses better morphology of spherical particles with well dispersion and uniform size distribution.

\subsection{Effect of Hydrolysis Time}

Figure 6 displays the SEM images of powders prepared with different hydrolysis time from $2 \mathrm{~h}$ to $72 \mathrm{~h}$ at $20^{\circ} \mathrm{C}$. As shown in Figure 6(a), numerous particles with
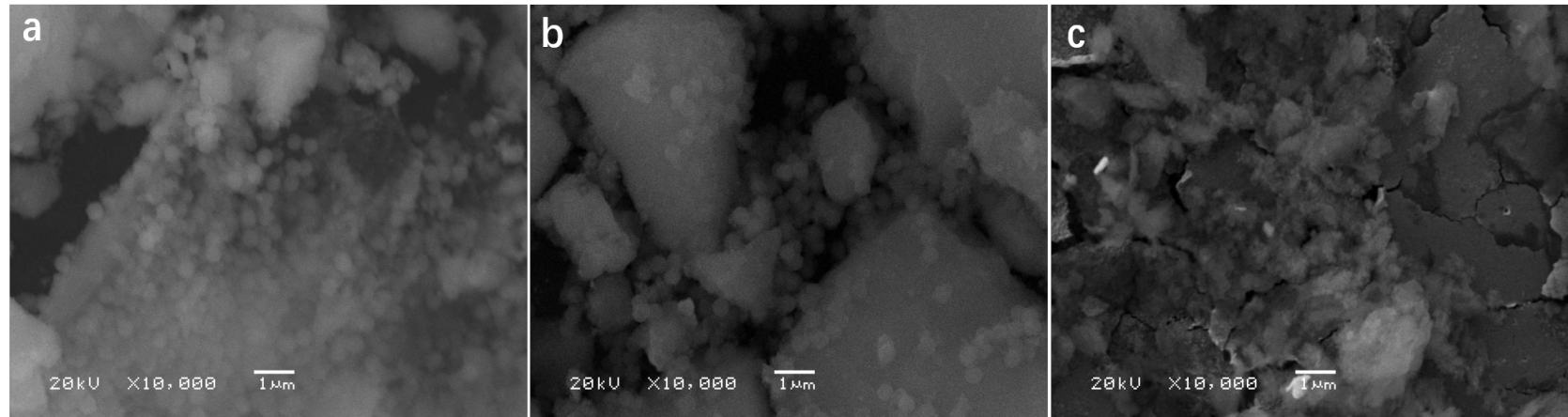

Figure 5. SEM images of $\mathrm{MgAl}_{2}(\mathrm{OH})_{8}$ with different amount of $\mathrm{MgAl}_{2}\left(\mathrm{OC}_{3} \mathrm{H}_{8}\right)_{8}:$ (a) $5 \mathrm{~g}$, (b) $10 \mathrm{~g}$ and (c) 15 g. The hydrolysis reaction time is $24 \mathrm{~h}$. 


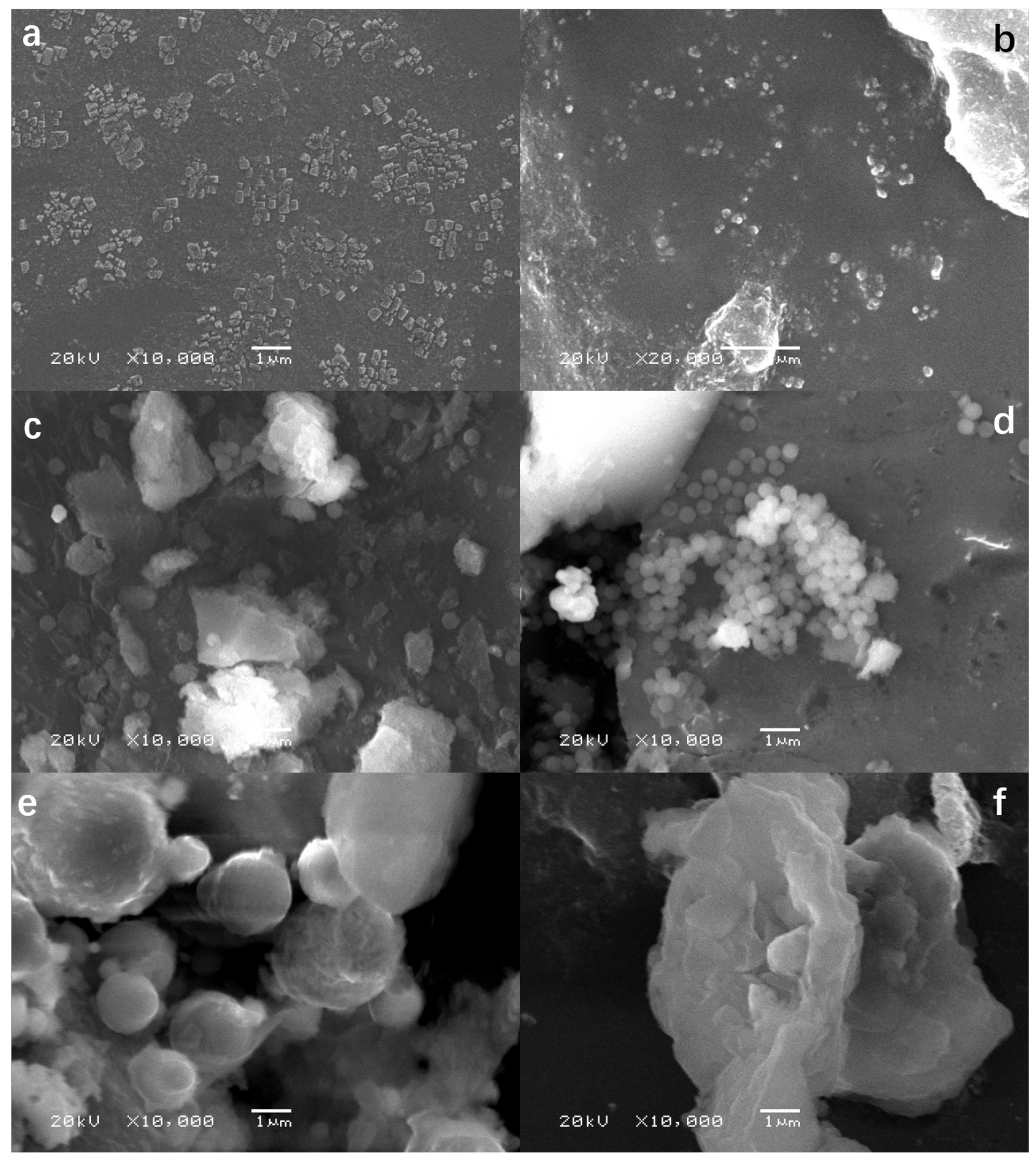

Figure 6. SEM images of $\mathrm{MgAl}_{2}(\mathrm{OH})_{8}$ prepared with different hydrolysis time: (a) $1 \mathrm{~h}$; (b) $2 \mathrm{~h}$; (c) 8 h; (d) 24 h; (e) $48 \mathrm{~h}$ and (f) 72 h.

angular, irregular shapes with a particle size of approximately $400 \mathrm{~nm}$ are observed under hydrolysis for $2 \mathrm{~h}$. Particles gradually grow to flocculated agglomerates under hydrolysis for $2 \mathrm{~h}$ in Figure 6(b). Extend the hydrolysis time directly to $8 \mathrm{~h}$ in Figure $6(\mathrm{c})$, it is found that most hydrolysate is detected to be agglomerates with various particle sizes and irregular shapes. But it still can be 
observed that a small amount of spherical or near-spherical particles are attached to the agglomerates. Along with the hydrolysis time for $24 \mathrm{~h}$ in Figure $6(\mathrm{~d})$, the as-prepared spherical particles gradually increase with uniform particle size of 300 to $400 \mathrm{~nm}$ and well-distribution, meanwhile, the agglomerates are gradually reduced. Continue to extend the reaction time to $48 \mathrm{~h}$ in Figure 6(e), spherical particles are found to gradually reduce with larger size and the irregularly agglomerates increase. Here, agglomeration occurs between particles and agglomerates. Until to $72 \mathrm{~h}$ the spherical particles disappeared, and all the substances obtained are flocculent agglomerates in Figure 6(f).

\subsection{Effect of Hydrolysis Temperature}

The hydrolysis temperature is considered to be another important factor that may influence the property of magnesium aluminum spinels. Table 4 and Figure 7 show the particle size, surface area and size distribution of samples hydrolysis at various temperatures from $20^{\circ} \mathrm{C}$ to $60^{\circ} \mathrm{C}$. The crystal growth rate and particle size greatly increase as the increasing hydrolysis temperature below $40^{\circ} \mathrm{C}$. The higher temperature results in the wider the particle size distribution. Analysis demonstrates that such phenomenon is caused by hydrolysis temperature, particularly at $50^{\circ} \mathrm{C}$ and $60^{\circ} \mathrm{C}$. Such high hydrolysis temperature causes

Table 4. The particle size and surface area of samples at different hydrolysis temperature from $20^{\circ} \mathrm{C}$ to $60^{\circ} \mathrm{C}$

\begin{tabular}{ccccc}
\hline Temperature $\left({ }^{\circ} \mathrm{C}\right)$ & $\mathrm{D} 10(\mu \mathrm{m})$ & $\mathrm{D} 50(\mu \mathrm{m})$ & $\mathrm{D} 90(\mu \mathrm{m})$ & $\begin{array}{c}\text { Surface area } \\
\left(\mathrm{m}^{2} / \mathrm{g}\right)\end{array}$ \\
\hline 20 & 3.729 & 10.362 & 19.874 & 6.44 \\
30 & 6.662 & 11.265 & 18.056 & 5.82 \\
40 & 8.034 & 17.020 & 31.283 & 6.74 \\
50 & 7.725 & 17.697 & 51.686 & 4.44 \\
60 & 1.019 & 16.538 & 84.880 & 5.65 \\
\hline
\end{tabular}

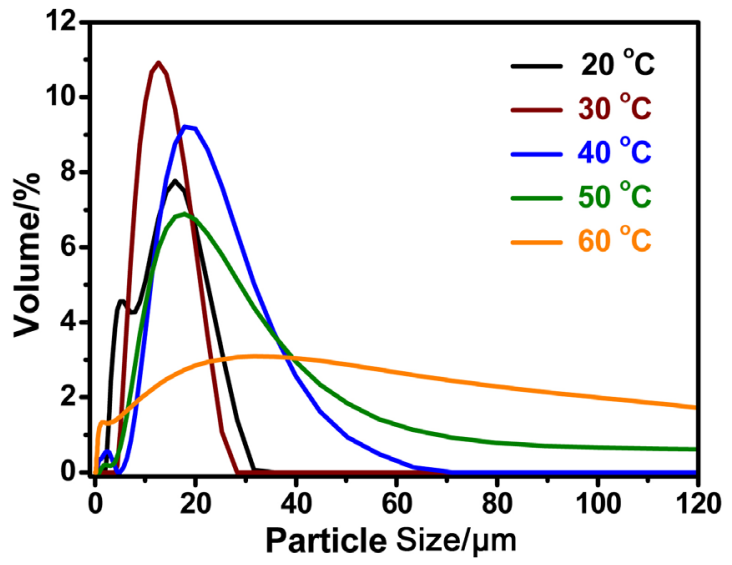

Figure 7. The particle size distribution of the samples with isopropanol as precursor solvent at hydrolysis temperature from $20^{\circ} \mathrm{C}$ to $60^{\circ} \mathrm{C}$. 
rapid formation of numerous crystals and later larger crystals become to generate. As a consequence, the optimal hydrolysis temperature is acquired to be $40^{\circ} \mathrm{C}$.

\subsection{Effect on Calcination Temperature}

Thermogravimetry and differential thermogravimetry (TG-DTG) curves were conducted on obtained powders with different types of alkoxides from $50^{\circ} \mathrm{C}$ to $900^{\circ} \mathrm{C}$ in Figure 8. In Figure 8(a), there are two stages for sample with ethanol as precursor with a total mass loss of $35 \%$ during the whole warming interval. During the lower temperature from $50^{\circ} \mathrm{C}$ to $200^{\circ} \mathrm{C}$, the weight loss is about $20 \%$ due to physical adsorption of water as well as residual solvent residues in the reaction. The weight loss of $15 \%$ is ascribed in the range of $200^{\circ} \mathrm{C}$ to $600^{\circ} \mathrm{C}$ as desorption of dihydroxylation from ethanol and chemical bond break between a trace amount of ethyl and magnesium or aluminum ions. After that, it turned to be stable without any weight loss. As shown in Figure 8(b) and Figure 8(c), there are three stages for samples with n-butanol and isopropanol as precursors
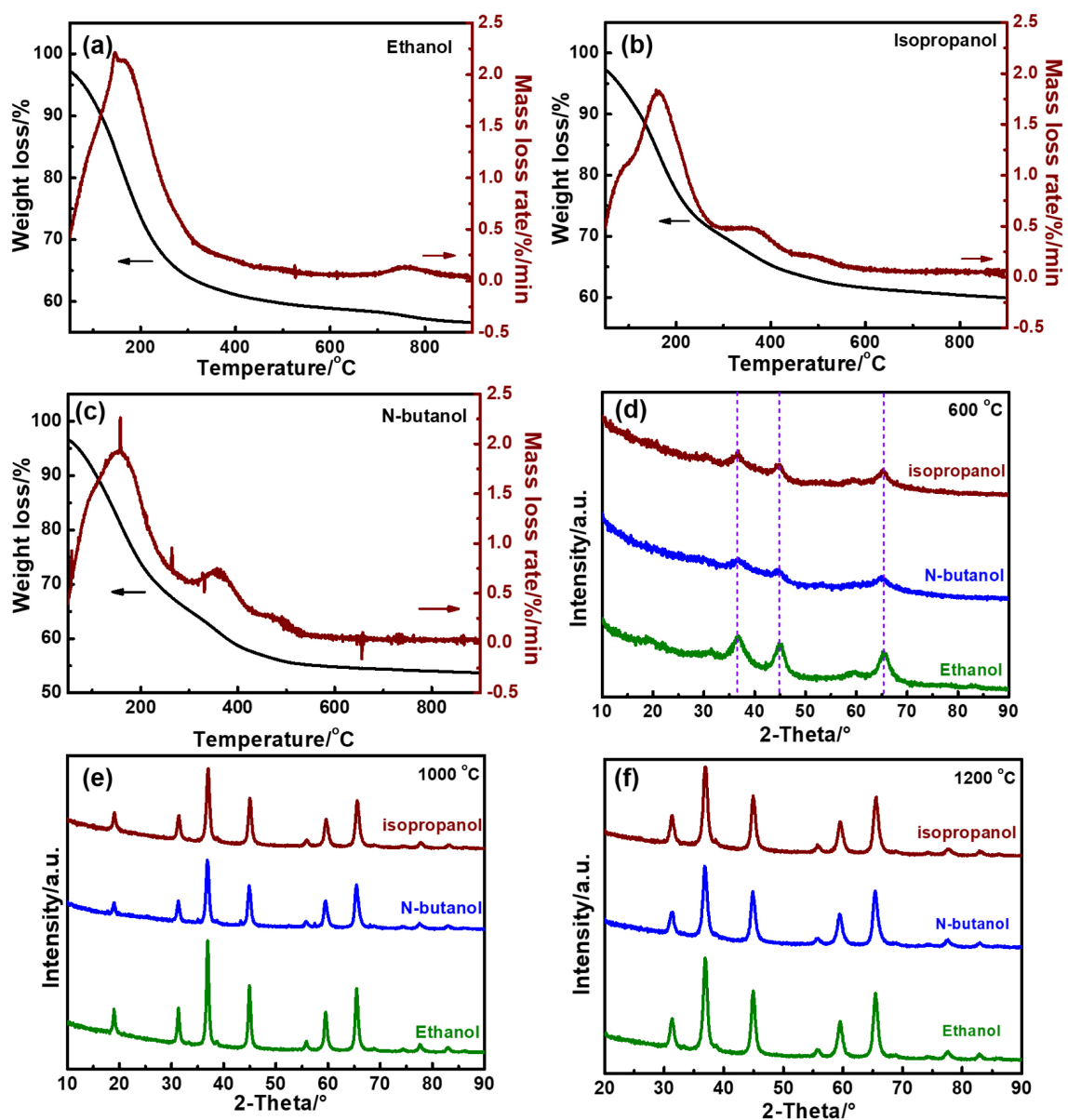

Figure 8. The TG-DTG curves of samples with different organic alcohols of (a) ethanol, (b) isopropanol and (c) n-butanol and (d) particle size distribution of corresponding samples with various magnesium aluminum bimetal alkoxide after dried $80^{\circ} \mathrm{C}$ and further hydrolysis; XRD patterns (e), (f) and (g) of samples with different organic alcohols treated at various temperature $\left(600^{\circ} \mathrm{C}, 1000^{\circ} \mathrm{C}\right.$ and $\left.1200^{\circ} \mathrm{C}\right)$. 
with total mass loss of $45 \%$ and $38 \%$, respectively. As for the first stage, the weight loss of $18 \%$ and $16 \%$ for $\mathrm{MgAl}_{2}(\mathrm{OH})_{8}$ prepared with n-butanol and isopropanol from $50^{\circ} \mathrm{C}$ to $200^{\circ} \mathrm{C}$ can be ascribed as physical adsorption of water as well as residual solvent residues in the reaction. For the second step, the weight loss of $20 \%$ and $18 \%$ for $\mathrm{MgAl}_{2}(\mathrm{OH})_{8}$ with n-butanol and isopropanol during $200^{\circ} \mathrm{C}$ to $400^{\circ} \mathrm{C}$ are due to dehydroxylation from the precursors. In the third period, slightly mass loss happens of $7 \%$ and $4 \%$ for samples with $n$-butanol and isopropanol from $400^{\circ} \mathrm{C}$ to $600^{\circ} \mathrm{C}$, which may be caused by a chemical bond break between a trace amount of residual butyl or isopropyl group and magnesium or aluminum ions. After that, no more weight loss occurs. An endothermic peak of precursor with $\mathrm{n}$-butanol is significantly larger than that of sample with isopropanol, indicating that preparation of sample with $n$-butanol needs more energy than that with isopropanol. Besides, both of precursors with n-butanol and isopropanol need more energy than that of ethanol. Additionally, the structure of obtained powders with various precursors of alkoxides was detected by XRD in Figure 8 and Table 5. As shown in Figures 8(d)-(f), XRD was conducted on samples prepared with various precursors of alkoxides and calcinated at a wide range temperature of $600^{\circ} \mathrm{C}, 1000^{\circ} \mathrm{C}$ and $1200^{\circ} \mathrm{C}$ for $3 \mathrm{~h}$. The result of $\mathrm{XRD}$ patterns clearly indicates that powders with various alkoxides are consistent well with pure magnesium aluminum spinel structure without too much change in the position of the diffraction peak. The lattice intensity enhances with the increasing temperature from $600^{\circ} \mathrm{C}$ to $1200^{\circ} \mathrm{C}$, indicating that the degree of crystallization of spinel increases with the increasing calcinated temperature. Based on the data in Figure 8(e), the intensity of diffraction peaks of sample with ethanol as alkoxide is significantly higher than that of n-butanol and isopropanol. It demonstrates that the required temperature for spinel phase with ethanol is low, which is consistent well with the data in Figure 8. On the other hand, the relative intensities of the diffraction peaks of each sample become smaller with the increasing temperature. Each sample displays the same relative intensities at $1200^{\circ} \mathrm{C}$ in Figure 8(f). Considering avoiding the severe aggregation of large particles at too much higher temperature, thus the optimal calcination temperature is selected to be $1200^{\circ} \mathrm{C}$.

As shown in Table 5, there is an obvious change of particle size among powders with ethanol, isopropanol and n-butanol as organic alcohol solvent in precursor preparation. The D50 of size distribution are $14.15 \mu \mathrm{m}, 17.70 \mu \mathrm{m}$ and 24.83 $\mu \mathrm{m}$ for sample with ethanol, isopropanol and n-butanol in Table 5, indicating that

Table 5. The particle size of samples with various alkoxides after treated at $1200^{\circ} \mathrm{C}$.

\begin{tabular}{ccccc}
\hline $\begin{array}{c}\text { Types of } \\
\text { alkoxides }\end{array}$ & $\mathrm{D} 10(\mu \mathrm{m})$ & $\mathrm{D} 50(\mu \mathrm{m})$ & $\mathrm{D} 90(\mu \mathrm{m})$ & Surface $\operatorname{area}\left(\mathrm{m}^{2} / \mathrm{g}\right)$ \\
\hline Ethanol & 7.981 & 14.146 & 28.045 & 4.51 \\
Isopropanol & 7.725 & 17.697 & 51.686 & 4.82 \\
N-butanol & 9.159 & 24.829 & 61.373 & 3.80
\end{tabular}


the particle size of powders increases with the increasing carbon chain of organic alcohol. Among them, the average particle size of the corresponding powder of $\mathrm{n}$-butanol is the smallest. Based on the analysis of particle size distribution, the particle size of isopropanol is relatively concentrated with largest specific surface area. As a result, $\mathrm{MgAl}_{2} \mathrm{O}_{4}$ with isopropanol as solvent for synthesis of precursor was better than that of ethanol and n-butanol in terms of particle size and corresponding distribution.

\section{Conclusion}

All in all, various synthetic parameters were deeply investigated on the preparation of $\mathrm{MgAl}_{2} \mathrm{O}_{4}$ via sol-gel followed by high temperature pyrolysis. The optimal preparation factors are as follows: 1) The alkoxide prepared with isopropanol possesses a larger surface area with uniform particle size; 2) Addition of ammonia with a $\mathrm{pH}$ of 8.5 can enhance the hydrolysis rate and rate of colloidal particles; 3 ) The point addition of $1.5 \mathrm{wt} \%$ of CTAB results in greatly reduced particle size with concentrated distribution of particles; 4) The moderate amount of alkoxide (10 g) with hydrolysis at $40^{\circ} \mathrm{C}$ for $24 \mathrm{~h}$ shows uniform particle and well-distribution; 5) the optimal calcination temperature of $1200^{\circ} \mathrm{C}$ introduces a pure magnesium aluminum spinel.

\section{Acknowledgements}

This work was partially supported by National Natural Science Fund of China (Grant Nos. 21606219).

\section{Conflicts of Interest}

The authors declare no conflict of interest.

\section{References}

[1] Rubat du Merac, M., Kleebe, H.J., Müller, M.M. and Reimanis, I.E. (2013) Fifty Years of Research and Development Coming to Fruition; Unraveling the Complex Interactions during Processing of Transparent Magnesium Aluminate $\left(\mathrm{MgAl}_{2} \mathrm{O}_{4}\right)$ Spinel. Journal of the American Ceramic Society, 96, 3341-3365.

https://doi.org/10.1111/jace.12637

[2] Hadian, N., Rezaei, M., Mosayebi, Z. and Meshkani, F. (2012) $\mathrm{CO}_{2}$ Reforming of Methane over Nickel Catalysts Supported on Nanocrystalline $\mathrm{MgAl}_{2} \mathrm{O}_{4}$ with High Surface Area. Journal of Natural Gas Chemistry, 21, 200-206. https://doi.org/10.1016/S1003-9953(11)60355-1

[3] Mosayebi, Z., Rezaei, M., Ravandi, A.B. and Hadian, N. (2012) Autothermal Reforming of Methane over Nickel Catalysts Supported on Nanocrystalline $\mathrm{MgAl}_{2} \mathrm{O}_{4}$ with High Surface Area. International Journal of Hydrogen Energy, 37, 1236-1242. https://doi.org/10.1016/j.ijhydene.2011.09.141

[4] Zhu, L.L., Park, Y.-J., Gan, L., Go, S.-I., Kim, H.-N., Kim, J.-M. and Ko, J.-W. (2018) Fabrication of Transparent $\mathrm{MgAl}_{2} \mathrm{O}_{4}$ from Commercial Nanopowders by Hot-Pressing without Sintering Additive. Materials Letters, 219, 8-11.

https://doi.org/10.1016/j.matlet.2018.02.010 
[5] Xu, W.W. and Dávila, L.P. (2018) Effects of Crystal Orientation and Diameter on the Mechanical Properties of Single-Crystal $\mathrm{MgAl}_{2} \mathrm{O}_{4}$ Spinel Nanowires. Nanotechnology, 30, Article ID: 055701.

https://iopscience.iop.org/article/10.1088/1361-6528/aaef11/meta https://doi.org/10.1088/1361-6528/aaef11

[6] Malekabadi, M.A. and Mamoory, R.S. (2018) Low-Temperature Synthesis of Micro/Nano Lithium Fluoride Added Magnesium Aluminate Spinel. Ceramics International, 44, 20122-20131. https://doi.org/10.1016/j.ceramint.2018.07.305

[7] Ding, D.H., Lv, L.H., Xiao, G.Q., Ren, Y., Yang, S.L., Yang, P. and Hou, X. (2019) One-Step Synthesis of in Situ Multilayer Graphene Containing $\mathrm{MgAl}_{2} \mathrm{O}_{4}$ Spinel Composite Powders. Ceramics International, 45, 6209-6215.

https://doi.org/10.1016/j.ceramint.2018.12.098

[8] Schneider, D., Mehlhorn, D., Zeigermann, P., Kärger, J. and Valiullin, R. (2016) Transport Properties of Hierarchical Micro-Mesoporous Materials. Chemical Society Reviews, 45, 3439-3467.

https://pubs.rsc.org/en/content/articlehtml/2016/cs/c5cs00715a https://doi.org/10.1039/C5CS00715A

[9] DeCanio, E.C. and Weissman, J.G. (1995) FT-IR Analysis of Borate-Promoted $\mathrm{Ni}-\mathrm{Mo} / \mathrm{Al}_{2} \mathrm{O}_{3}$ Hydrotreating Catalysts. Colloids and Surfaces A: Physicochemical and Engineering Aspects, 105, 123-132. https://doi.org/10.1016/0927-7757(95)03307-3

[10] Habibi, N., Wang, Y., Arandiyan, H. and Rezaei, M. (2017) Low-Temperature Synthesis of Mesoporous Nanocrystalline Magnesium Aluminate $\left(\mathrm{MgAl}_{2} \mathrm{O}_{4}\right)$ Spinel with High Surface Area Using a Novel Modified Sol-Gel Method. Advanced Powder Technology, 28, 1249-1257. https://doi.org/10.1016/j.apt.2017.02.012

[11] Areán, C.O., Mentruit, M.P., López, A.L. and Parra, J. (2001) High Surface Area Nickel Aluminate Spinels Prepared by a Sol-Gel Method. Colloids and Surfaces A: Physicochemical and Engineering Aspects, 180, 253-258. https://doi.org/10.1016/S0927-7757(00)00590-2

[12] Liu, W., Yang, J.L., Xu, H., Wang, Y.Z., Hu, S.L. and Xue, C.Y. (2013) Effects of Chelation Reactions between Metal Alkoxide and Acetylacetone on the Preparation of $\mathrm{MgAl}_{2} \mathrm{O}_{4}$ Powders by Sol-Gel Process. Advanced Powder Technology, 24, 436-440. https://doi.org/10.1016/j.apt.2012.09.006

[13] Parmentier, J., Richard-Plouet, M. and Vilminot, S. (1998) Influence of the Sol-Gel Synthesis on the Formation of Spinel $\mathrm{MgAl}_{2} \mathrm{O}_{4}$. Materials Research Bulletin, 33, 1717-1724. https://doi.org/10.1016/S0025-5408(98)00169-X

[14] Suyama, Y. and Kato, A. (1982) Characterization and Sintering of Mg-Al Spinel Prepared by Spray-Pyrolysis Technique. Ceramics International, 8, 17-21. https://doi.org/10.1016/0272-8842(82)90010-4

[15] Rashad, M., Zaki, Z. and El-Shall, H. (2009) A Novel Approach for Synthesis of Nanocrystalline $\mathrm{MgAl}_{2} \mathrm{O}_{4}$ Powders by Co-Precipitation Method. Journal of Materials Science, 44, 2992-2998.

https://link.springer.com/article/10.1007/s10853-009-3397-8 https://doi.org/10.1007/s10853-009-3397-8

[16] Navaei Alvar, E., Rezaei, M., Navaei Alvar, H., Feyzallahzadeh, H. and Yan, Z.-F. (2009) Synthesis of Nanocrystalline $\mathrm{MgAl}_{2} \mathrm{O}_{4}$ Spinel by Using Ethylene Diamine as Precipitation Agent. Chemical Engineering Communications, 196, 1417-1424. https://doi.org/10.1080/00986440902939012

[17] Amini, M., Mirzaee, M. and Sepanj, N. (2007) The Effect of Solution Chemistry on 
the Preparation of $\mathrm{MgAl}_{2} \mathrm{O}_{4}$ by Hydrothermal-Assisted Sol-Gel Processing. Materials Research Bulletin, 42, 563-570.

https://doi.org/10.1016/j.materresbull.2006.06.011

[18] Balabanov, S., Vaganov, V., Gavrishchuk, E., Drobotenko, V., Permin, D. and Fedin, A. (2014) Effect of Magnesium Aluminum Isopropoxide Hydrolysis Conditions on the Properties of Magnesium Aluminate Spinel Powders. Inorganic Materials, 50, 830-836. https://link.springer.com/article/10.1134/S0020168514080032 https://doi.org/10.1134/S0020168514080032

\section{Supplement}

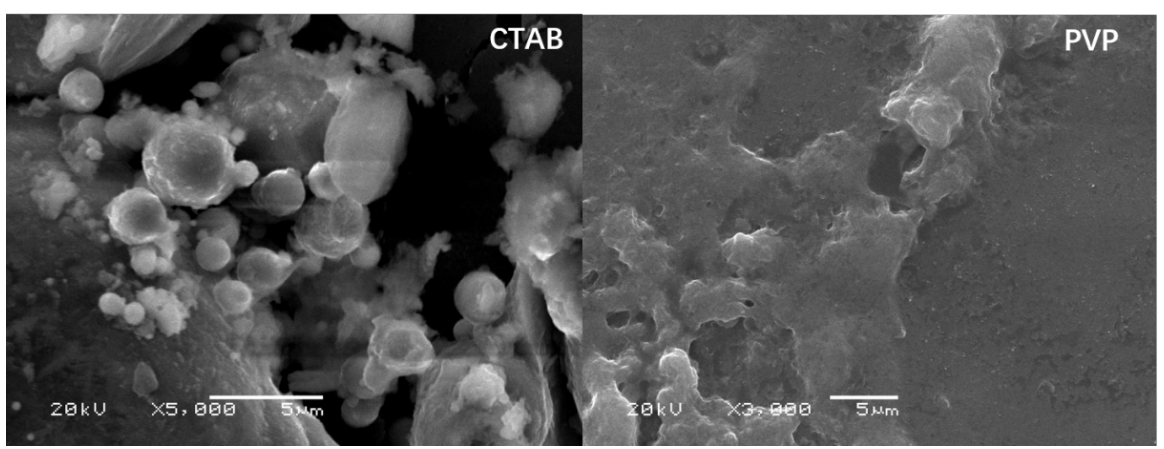

Figure S1. SEM images of $\mathrm{MgAl}_{2}\left(\mathrm{OC}_{3} \mathrm{H}_{8}\right)_{8}$ with dispersant of (a) CTAB and (b) PVP. 